\section{Pacific Northwest}

National Laboratory

Operated by Battelle for the

U.S. Department of Energy

\title{
Report on the Power and Detector Stability Measurements for the QC Laser Alignment System
}

\author{
T. L. Myers \\ R. Suarez \\ C. A. Bonebrake \\ T. L. Stewart \\ B. D. Cannon \\ B. K. Hatchell
}

November 2003

Prepared for the U.S. Department of Energy under Contract DE-AC06-76RL01830 


\title{
DISCLAIMER
}

This report was prepared as an account of work sponsored by an agency of the United States Government. Neither the United States Government nor any agency thereof, nor Battelle Memorial Institute, nor any of their employees, makes any warranty, express or implied, or assumes any legal liability or responsibility for the accuracy, completeness, or usefulness of any information, apparatus, product, or process disclosed, or represents that its use would not infringe privately owned rights. Reference herein to any specific commercial product, process, or service by trade name, trademark, manufacturer, or otherwise does not necessarily constitute or imply its endorsement, recommendation, or favoring by the United States Government or any agency thereof, or Battelle Memorial Institute. The views and opinions of authors expressed herein do not necessarily state or reflect those of the United States Government or any agency thereof.

\author{
PACIFIC NORTHWEST NATIONAL LABORATORY \\ operated by \\ BATTELLE \\ for the \\ UNITED STATES DEPARTMENT OF ENERGY \\ under Contract DE-AC06-76RL01830
}

Printed in the United States of America

$$
\begin{gathered}
\text { Available to DOE and DOE contractors from the } \\
\text { Office of Scientific and Technical Information, } \\
\text { P.O. Box 62, Oak Ridge, TN 37831-0062; } \\
\text { ph: (865) 576-8401 } \\
\text { fax: }(865) \text { 576-5728 } \\
\text { email: reports@adonis.osti.gov }
\end{gathered}
$$

\author{
Available to the public from the National Technical Information Service, \\ U.S. Department of Commerce, 5285 Port Royal Rd., Springfield, VA 22161 \\ ph: (800) 553-6847 \\ fax: $(703) 605-6900$ \\ email: orders@ntis.fedworld.gov \\ online ordering: http://www.ntis.gov/ordering.htm
}

This document was printed on recycled paper. 


\section{Report on the Power and Detector Stability Measurements for the QC Laser Alignment System}
T. L. Myers
R. Suarez
C. A. Bonebrake
T. L. Stewart
B. D. Cannon
B. K. Hatchell

November 2003

Prepared for the U.S. Department of Energy

under Contract DE-AC06-76RL01830 


\section{Summary}

This report summarizes the preliminary tests that PNNL has performed to date for a Quantum Cascade (QC) Laser Alignment System that is being developed. PNNL is designing, fabricating, assembling, and testing the QC Laser Alignment System and has a subcontract with Maxion Technologies, Inc. for development and production of the QC laser devices to be used in this system. The QC lasers furnished by Maxion will be incorporated into the QC Laser Alignment System by PNNL. The QC Laser Alignment System consists of five Alignment Source Assemblies (ASAs) and a computer control system with graphical user interface (GUI). Each ASA has two QC lasers along with a temperature sensor. The system design also includes an optical detector for each QC laser to measure the output power of the rear facet for additional stabilization. The system will monitor the voltage across the QC laser, the temperature, the current, and the signal from the optical detectors to ensure the system is within the tolerances specified in the System Specifications. The System Specifications require that the relative power between lasers on the same ASA be maintained at $\pm 1 \%$ and among the lasers on different ASAs at $\pm 2.5 \%$. For the tests reported here, we attempted to examine the power stability of the QC laser as well as the variability of the optical detectors to ensure the system will adhere to these specifications.

These preliminary tests did not incorporate the actual ASA mounting scheme or the QC lasers that are being fabricated by Maxion to operate at the specified temperature of $-50^{\circ} \mathrm{C}$. Thus, we expect the performance from these results to differ from the actual results that can be achieved in the QC Laser Alignment System. Current limitations with the mounting scheme created problems with the power stability due to thermal cycling. Short-term power stability where thermal cycling was not a problem showed power fluctuations within the $1 \%$ tolerance limits. Once thermal cycling was introduced, however, larger variations resulted although most measurements were still within the $2.5 \%$ tolerance limits. Unfortunately, problems with the mount worsened, which contributed to a drop in power for the long-term measurements, until finally we lost electrical contact with the device. The variability tests for the optical detectors were encouraging and show that monitoring the light from the rear facet of the QC laser should provide sufficient feedback to maintain the QC lasers within the system specifications. 


\section{Contents}

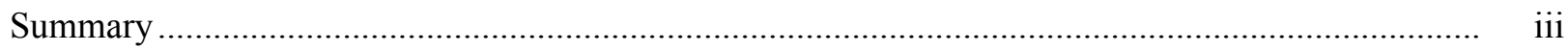

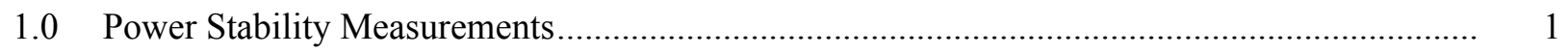

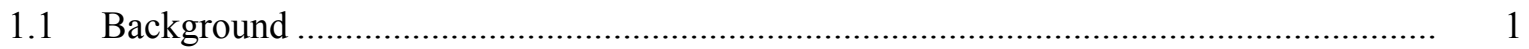

1.2 Short-Term Power Stability Tests ............................................................................ 3

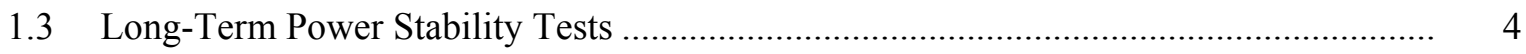

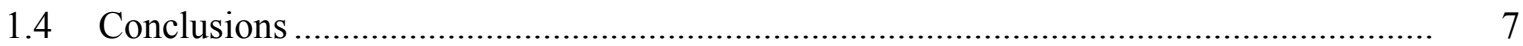

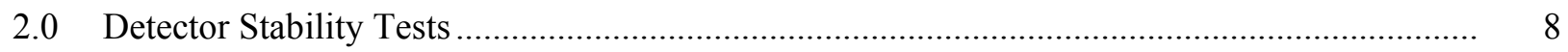

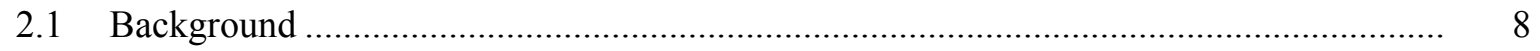

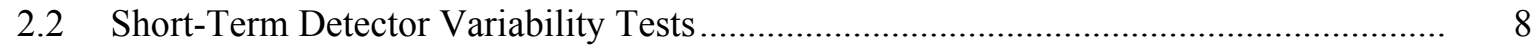

2.3 Long-Term Detector Variability Tests ….............................................................. 9

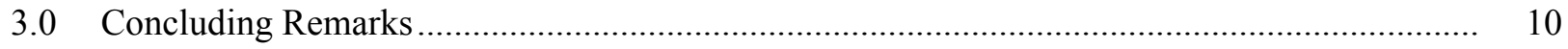




\section{Figures}

1 Side View of Conventional QC Laser Mounting Scheme ................................................... 1

2 Top View of Cold Finger and QC Laser Sub-mount ............................................................ 2

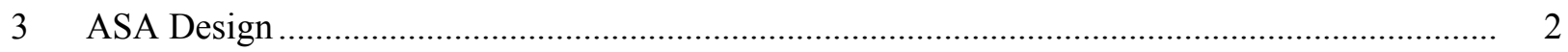

4 QC Short-Term Power Stability …............................................................................. 3

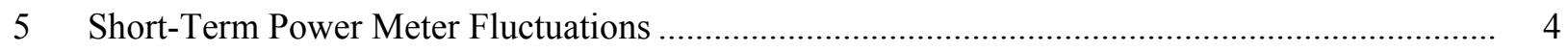

6 Power Measurements Over 6 Non-Consecutive Days ................................................... 5

$7 \quad$ Power Measurements Over 5 Consecutive Days …........................................................ 5

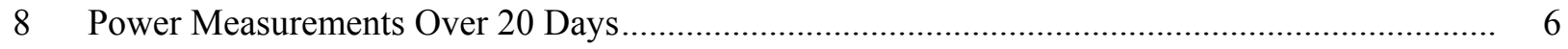

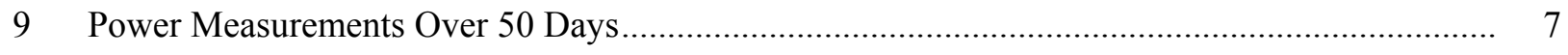

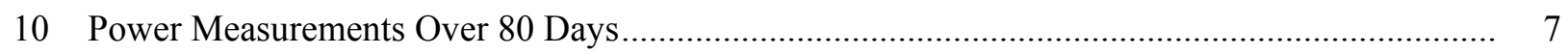

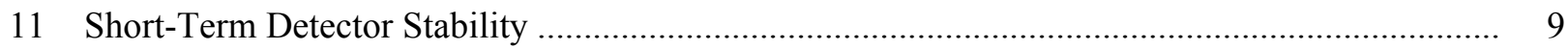

12 Detector Stability Measurements Over 80 Days............................................................. 9 


\subsection{Power Stability Measurements}

\subsection{Background}

These tests examine the power stability of a conventional single-mode QC laser when the test system is operated at a set current and temperature. These tests use a QC laser at cryogenic temperatures because the high-performance QC lasers, which are being designed to operate continuously at $-50^{\circ} \mathrm{C}$, will not be delivered to PNNL until the end of October 2003. The test set-up involves a QC laser soldered onto a copper sub-mount that is pushed down onto the cold finger mounted inside a cryogenically cooled dewar as shown in Figure 1. A thin layer of thermal grease is applied between the sub-mount and the cold finger to increase thermal contact. Figure 2 shows the temperature sensor and heater, which are located on the middle of the cold finger. A Keithley 238 High Current Source Measuring Unit with a fractional stability $<20 \mathrm{ppm}$ supplies the current to the QC laser and a Lakeshore 332S temperature controller maintains the temperature of the cold finger to $\leq 0.02^{\circ} \mathrm{K}$. Both of these components will also be used in the QC Laser Alignment System. We use a Molectron PM3 power probe and a Molectron PM5200 power meter to measure the output power. The reported overall accuracy of the power meter is $3 \%$ with a minimum resolution of $10 \mu \mathrm{W}$. The thermal probe has a $19-\mathrm{mm}$ aperture and is placed in front of the dewar to collect most of the uncollimated light from the front facet of the QC laser. Shielding is placed around the power meter to reduce thermal drift. We zero the instrument with the laser below threshold.

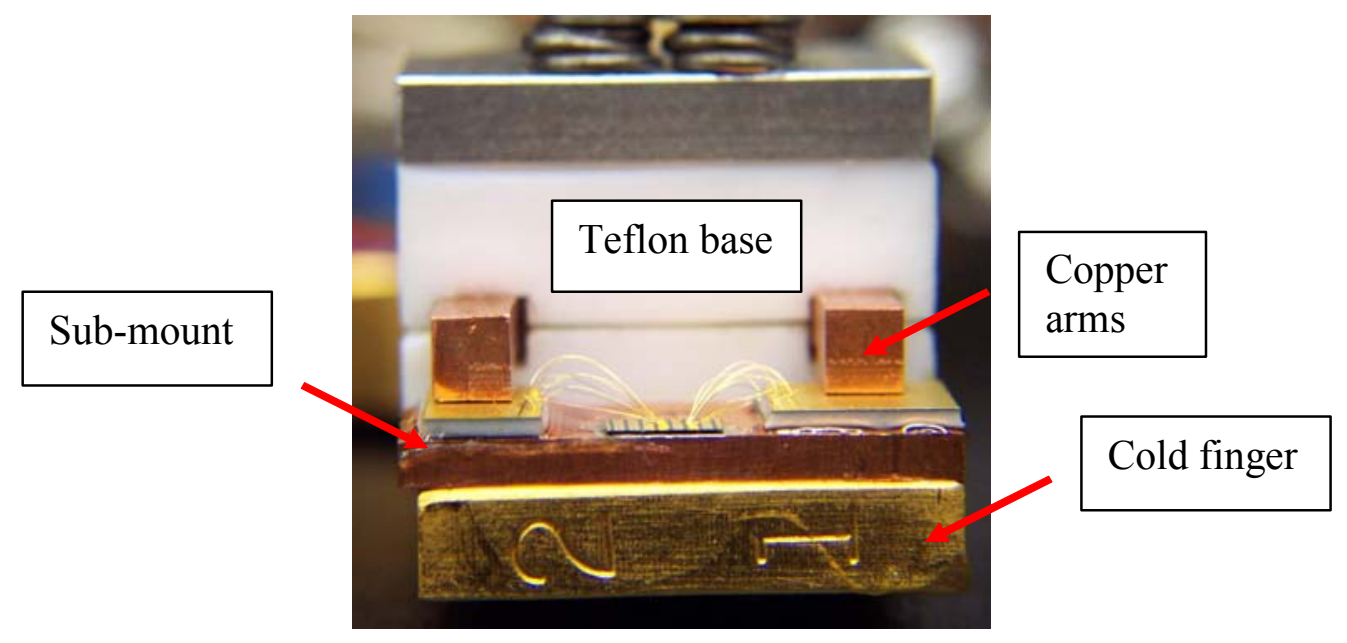

Figure 1. Side View of Conventional QC Laser Mounting Scheme 


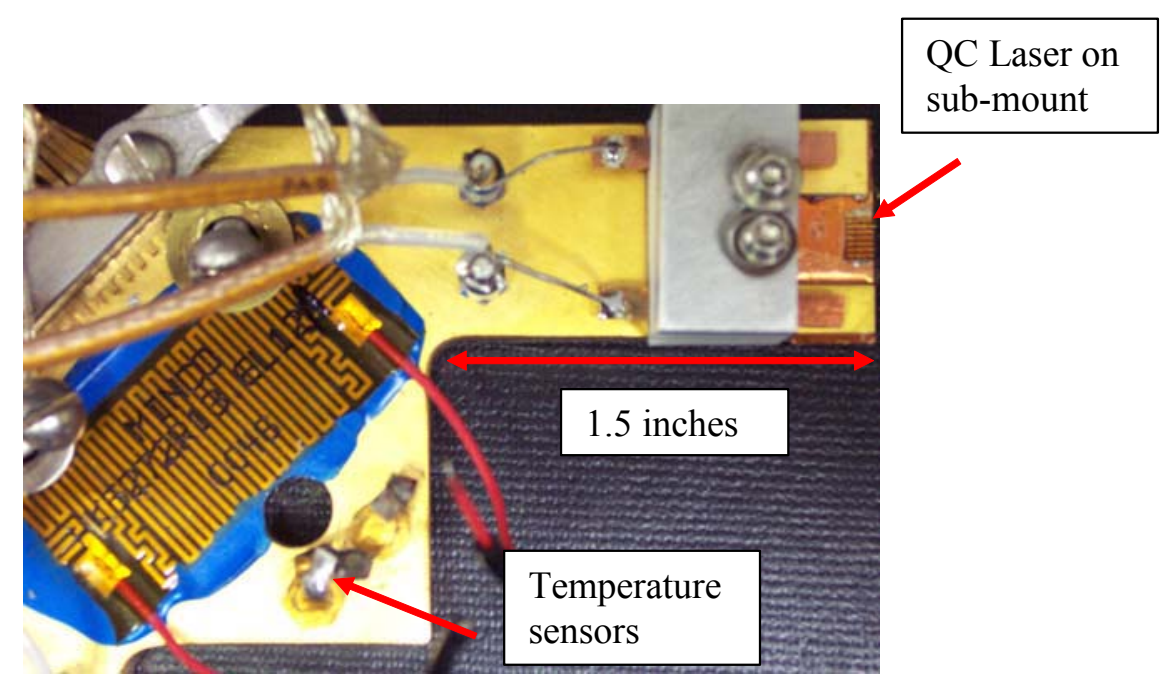

Figure 2. Top View of Cold Finger and QC Laser Sub-mount

The main problem in this test set-up is the interface between the sub-mount and the cold finger. With cryogenic cooling, the Teflon base that presses down on the copper arms contracts and can result in losing electrical contact. Because this method also provides the force needed to maintain good thermal contact between the sub-mount and the cold finger, the actual temperature at the QC can change significantly even though the cold finger temperature is maintained. For better temperature stability, a better mounting scheme is needed with the sensor mounted closer to the QC laser and on the same surface. In the actual ASA design shown in Figure 3, the QC lasers will be soldered directly to the ASA mount with the temperature sensor between the two lasers. The current leads will also be soldered directly to the gold pads instead of using a Teflon mount. Thus, the design for the QC Laser Alignment System should provide higher performance and be less sensitive to thermal cycling.

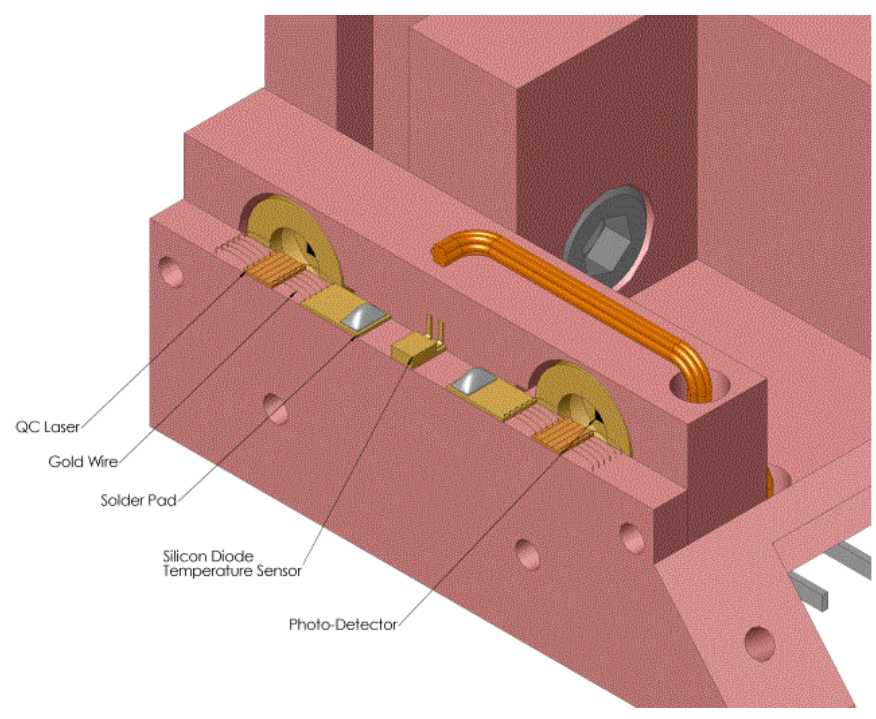

Figure 3. ASA Design 
The other limitation in the current set-up is that we are employing only a two-wire scheme to measure the QC voltage. A four-wire measurement should be used for high-current and high-precision applications. In a four-wire measurement system, separate wires are used for current supply and voltage measurement. The current supply wires have a resistance and so there is a voltage drop across these wires. The voltage sense wires do not carry any current and so there is no significant voltage drop. Thus, it would be more accurate than the two-wire scheme where the same two wires are used for current supply and voltage sensing. Thus, in the current set-up, we are measuring the voltage drop across the load as well as across the wires. Since the voltage drop is not sensed at the QC laser, we cannot use the measured voltage as an effective indicator of the QC temperature. In the QC Laser Alignment System, PNNL is using a four-wire measurement scheme.

\subsection{Short-Term Power Stability Tests}

PNNL first looked at the short-term power stability of the QC laser at a set current and temperature. The current was set to $-430 \mathrm{~mA}$, and the temperature of the cold finger was maintained at $91.41^{\circ} \mathrm{K}$. Before we take measurements, we first fill the dewar with liquid nitrogen and turn on the heater for the cold finger once the dewar has cooled down. We then turn on the current to the QC laser below threshold and zero the power meter. After we ramp up the current to $-430 \mathrm{~mA}$, we usually let the system equilibrate for about 5 minutes and then begin recording the power. Figure 4 shows the power stability for the QC laser over almost 2 hours of continuous operation. The solid red line illustrates the mean power, the dashed red lines shows the $1 \%$ range, and the dashed black lines encompass the $2.5 \%$ range. The mean power is equal to $5.90 \pm 0.01 \mathrm{~mW}$ (the error estimates are reported as \pm two standard deviations). Longer measurement times were difficult because of thermal drift in the power meter. The fluctuations are less than $1 \%$ and are limited by power meter fluctuations. Figure 5 shows typical fluctuations that can be observed in the power meter. We record the data in this plot by operating the laser at $-300 \mathrm{~mA}$, which is $40 \mathrm{~mA}$ below lasing threshold, and zeroing the power meter prior to the measurement. The peak-to-peak variation is as much as $0.3 \mathrm{~mW}$, which is similar to the drift observed in Figure 3.

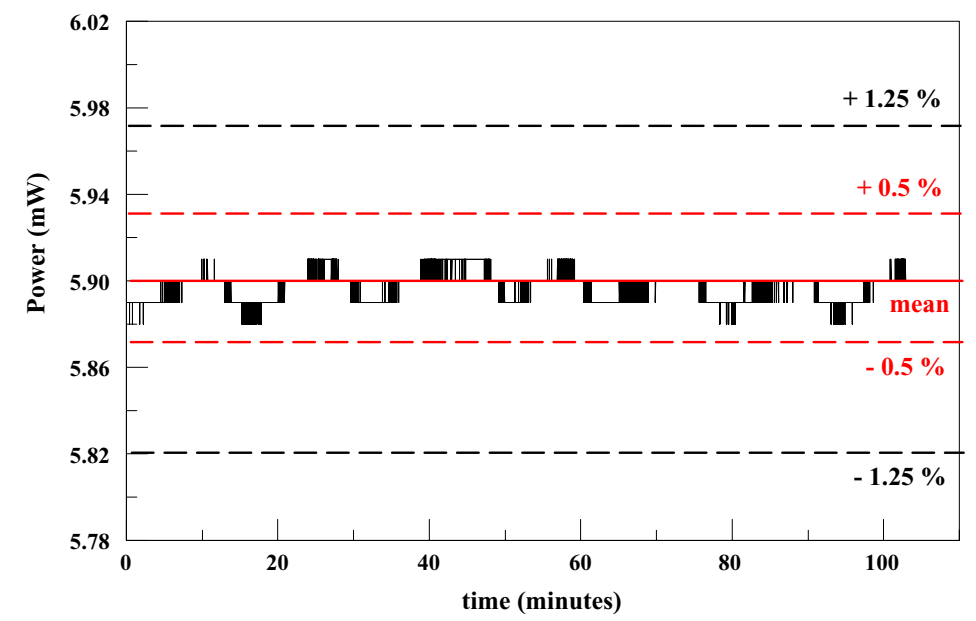

Figure 4. QC Short-Term Power Stability 


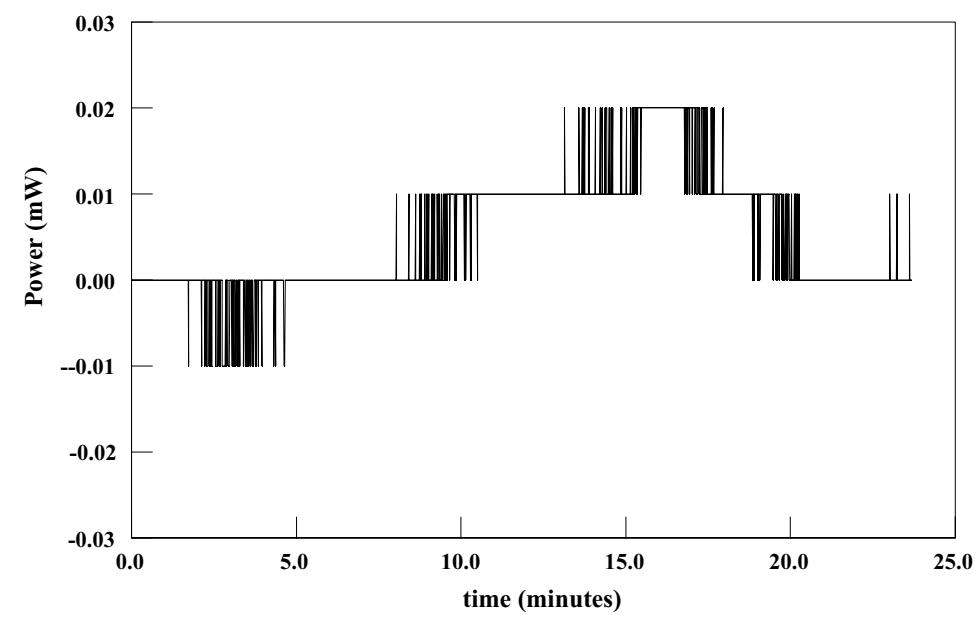

Figure 5. Short-Term Power Meter Fluctuations

\subsection{Long-Term Power Stability Tests}

PNNL also wanted to monitor the long-term power stability of the QC laser, including the effect of turning the system on and off. In these measurements, the power is recorded for approximately 15 minutes with the current of the QC laser maintained at $-430 \mathrm{~mA}$, which is $90 \mathrm{~mA}$ above threshold, and the temperature of the cold finger set to $91.41^{\circ} \mathrm{K}$. Figure 6 shows data taken over 6 days (the error bars reflect the standard deviation, $1 \sigma$ ). Although all of the measurements are within the $2.5 \%$ tolerance, one-third of the data are outside of the $1 \%$ range. These initial measurements showed that throughout the day, the power could increase by as much as $2 \%$ so that the power was dependent upon how long the QC laser had been operating. For example, the data on June 17 and June 20, where measurements were taken at different times during the day, show the power increases with subsequent measurements. Also, the two lowest readings in Figure 6 resulted when the current and heater were not on for a significant period of time before taking the measurement, whereas the two highest data points occurred after the current and heater had been on for most of the day. These results suggest the thermal contact between the QC laser and the cold finger is changing depending on how long the current and heater had been turned on the system. 


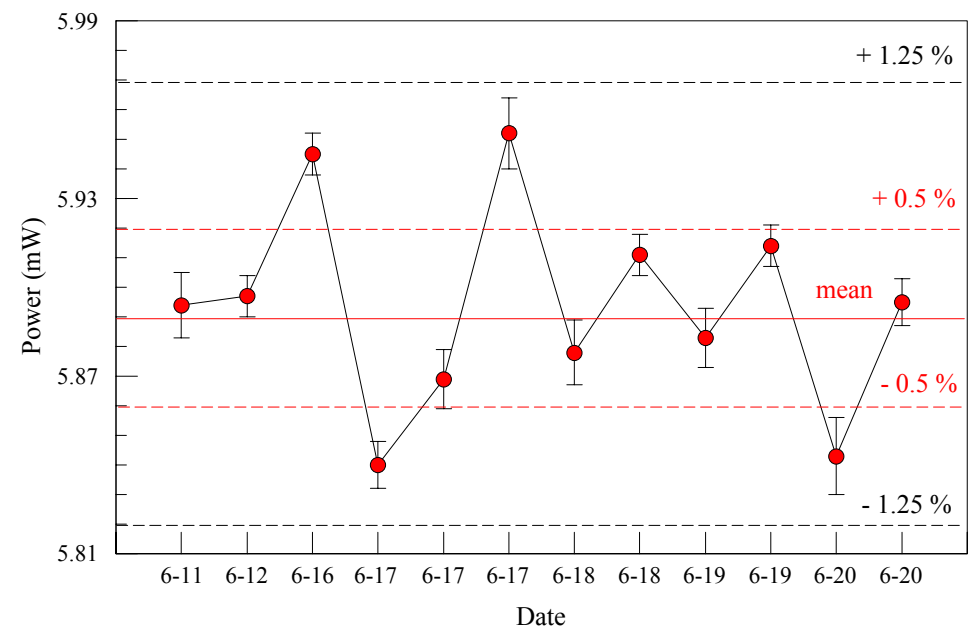

Figure 6. Power Measurements Over 6 Non-Consecutive Days

PNNL began to monitor and record the voltage across the QC to provide another indicator of performance. This measurement could potentially be used to provide an accurate probe of the temperature at the QC laser. As we already discussed, the test set-up does not provide an accurate reading of the voltage drop across the QC laser because we are not using the Keithley Source Measuring Unit in the proper remote sensing configuration. Regardless, the voltage measurements did show a steady decrease in the voltage with time along with a steady increase in power. A lower voltage can indicate better thermal contact between the sub-mount and the cold finger resulting in a lower temperature at the active region and thus higher power. Therefore, we began to operate the QC laser at a higher current $(-700 \mathrm{~mA})$ for an hour to let the system equilibrate before taking data at the lower current. Figure 7 shows the ensuing power measurements over 5 consecutive days. On days when we recorded multiple measurements, we no longer observe the power increasing throughout the day, and the power fluctuations over the entire week were less than $1 \%$.

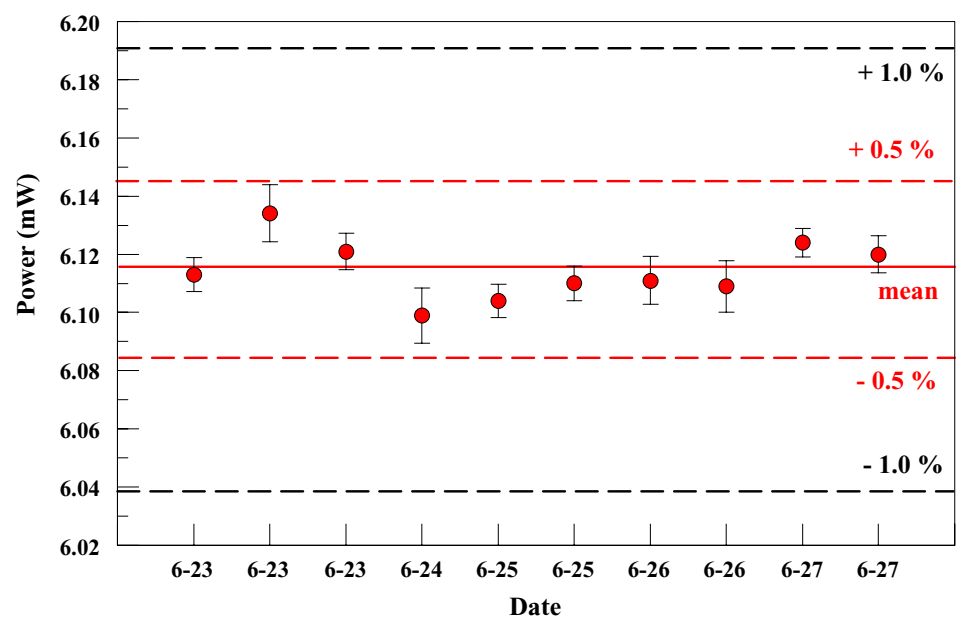

Figure 7. Power Measurements Over 5 Consecutive Days 
PNNL continued these measurements for another two weeks. Figure 8 shows the data taken from June 23 to July 11 . Most of the measurements are within $1 \%$ of the mean value and are all within the $2.5 \%$ range. The largest variations are observed when we resumed measurements after the system sat idle for a couple of days and the dewar warmed back up to room temperature. The thermal cycling from $300 \mathrm{~K}$ down to $77 \mathrm{~K}$ leads to problems with the contact between the sub-mount and cold finger because the mounting scheme used in these tests is particularly sensitive to thermal cycling. In fact, these measurements had to be discontinued because eventually we lost electrical contact with the QC laser and discovered a vacuum leak in the dewar used to cryogenically cool the QC laser. Better performance is expected in the QC Laser Alignment System because the thermal cycling is less severe and the thermal contact will be improved.

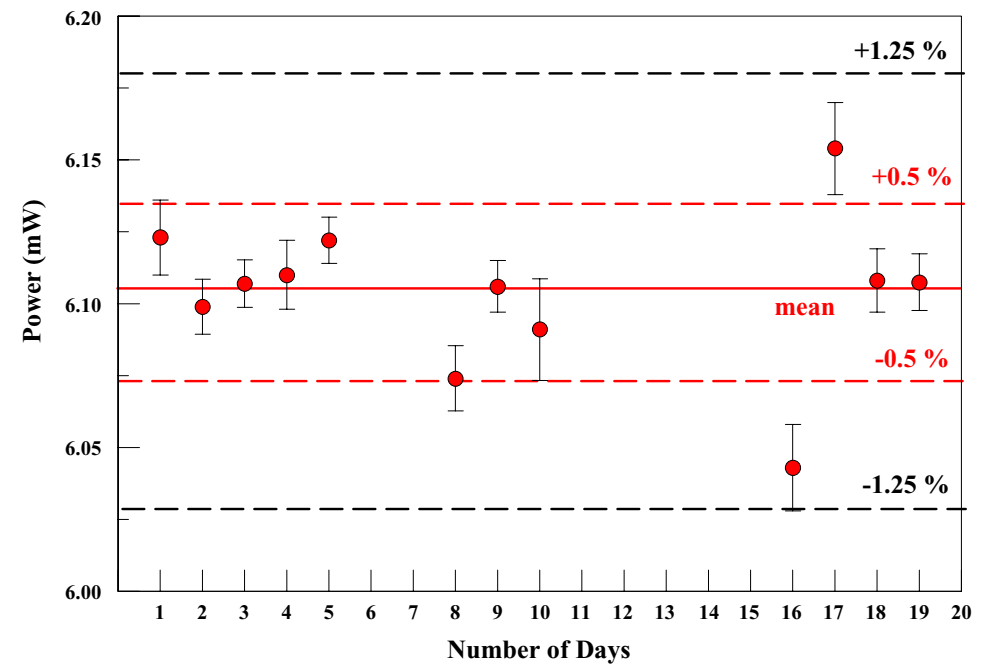

Figure 8. Power Measurements Over 20 Days

After we re-mounted the QC laser into another dewar, we resumed the power measurements. Unfortunately, these results cannot be compared with previous measurements because we cannot guarantee the temperature of the QC is the same. Figure 9 shows the recorded power over almost 50 days for these new measurements. After the first 11 measurements, we began to measure the power only twice a week so thermal cycling occurs after each measurement. After the first week of testing, we observe larger fluctuations in the power. In fact, some measurements are beyond the $2.5 \%$ tolerance.

We continued these tests for another 32 days until October 20, 2003. As shown in Figure 10, for these remaining measurements, the power began to drop. This power loss is most likely resulting from inefficient thermal contact and not due to degradation of the QC laser. In fact, electrical contact with the QC laser was lost after the last measurement with cryogenic cooling. 


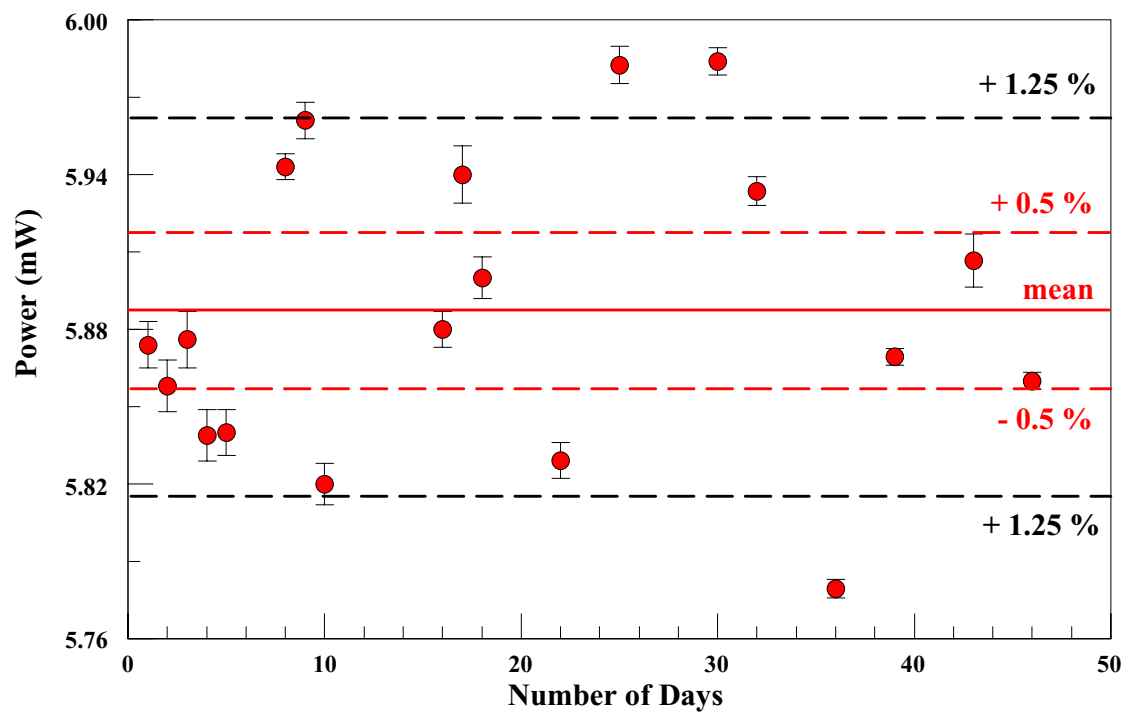

Figure 9. Power Measurements Over 50 Days

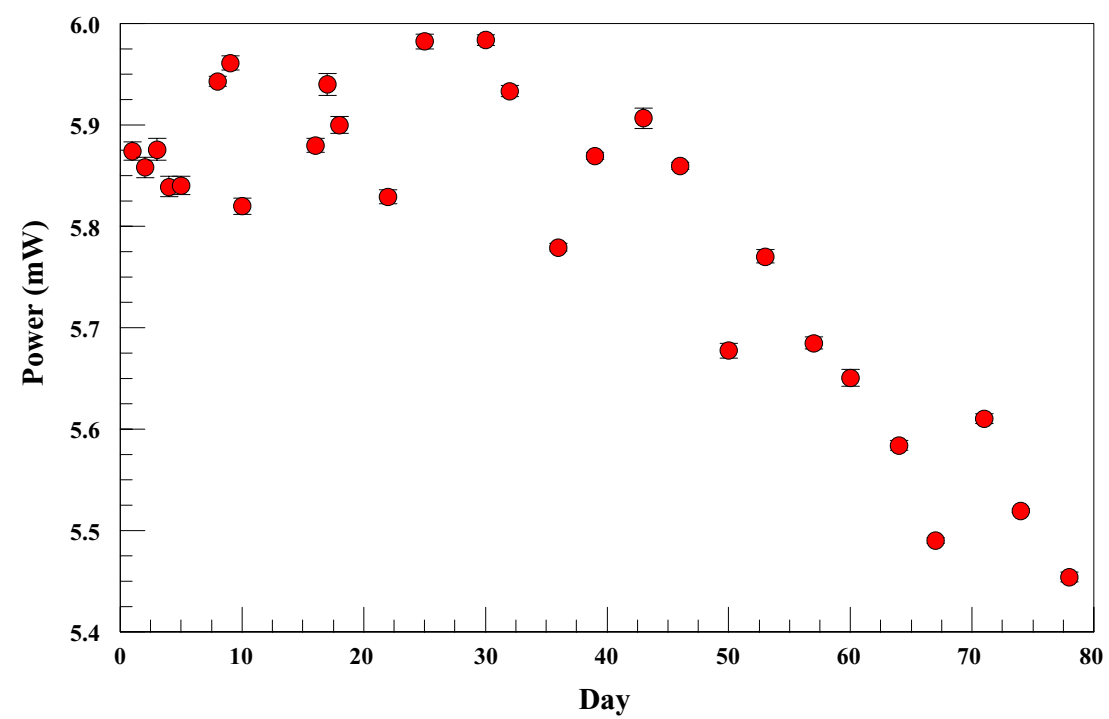

Figure 10. Power Measurements Over 80 Days

\subsection{Conclusions}

Based on these test results, we can no longer guarantee that the power stability can be achieved with just current and temperature stability without testing the actual QC Laser Alignment System. More convincing tests are needed to monitor the power stability of the QC laser mounted on an ASA at $-50^{\circ} \mathrm{C}$. We expect improved performance with this configuration because both the QC lasers and the electrical leads to the QC laser are directly soldered to the sub-mount providing better thermal and electrical 
contact. Also, the temperature sensor will be on the same interface as the QC laser, which will allow us to control the temperature of the active region more effectively. Thus, the power should be more stable for the QC Laser Alignment System.

\subsection{Detector Stability Tests}

\subsection{Background}

Because PNNL must be confident that the QC Laser Alignment System maintains the power stability of the QC laser given by the System Specifications, PNNL is planning to use optical detectors to measure the output from the rear facet of each QC laser as an additional safeguard. These tests examined the detector variability by looking at drifts between two detectors measuring light from the same source. We wanted to verify that we could achieve the required sensitivity from the detectors to measure changes in power at the $1 \%$ level.

The optical detectors used in these tests are similar to the detectors that will be used in the QC Laser Alignment System. In these tests, we use thermoelectrically cooled photovoltaic detectors from Vigo (PDI-2TE-10.6) with a 1-mm active area. A chopper is used to modulate the signal because the detectors have AC-coupled pre-amplifiers integrated in the base; thus, thermal drift is not a problem. Two Agilent 34401A 6 $1 \frac{2}{2}$ digit multi-meters read the voltage and PNNL records the signal on each detector. We compare the ratio between the two detectors to see if any drifts between the two detectors occur.

The original test scheme used a Fabry-Perot QC laser at a set current and temperature as the optical source. We collimated the light from the QC laser using a custom lens system mounted on the outside of the dewar. We used another lens to focus the beam onto the two detectors and a polarization-sensitive beamsplitter to split the light onto the two detectors. During the course of a measurement, this ratio could vary by more than $5 \%$. Several factors can cause these abrupt changes such as polarization fluctuations, pointing instabilities, and drifts in the alignment. Therefore, we abandoned using a QC laser as the optical source and began to use a blackbody source.

\subsection{Short-Term Detector Variability Tests}

In these tests, the blackbody radiation at $756 \mathrm{~K}$ is directed towards the two detectors without any further focusing. We measured the short-term variability of the optical detectors over approximately 2 hours. Figure 11 plots the ratio of the signal on the two detectors as a function of the measurement time. Over this timescale, the peak-to-peak fluctuations are less than $0.5 \%$, which is well within the $1 \%$ tolerance. 


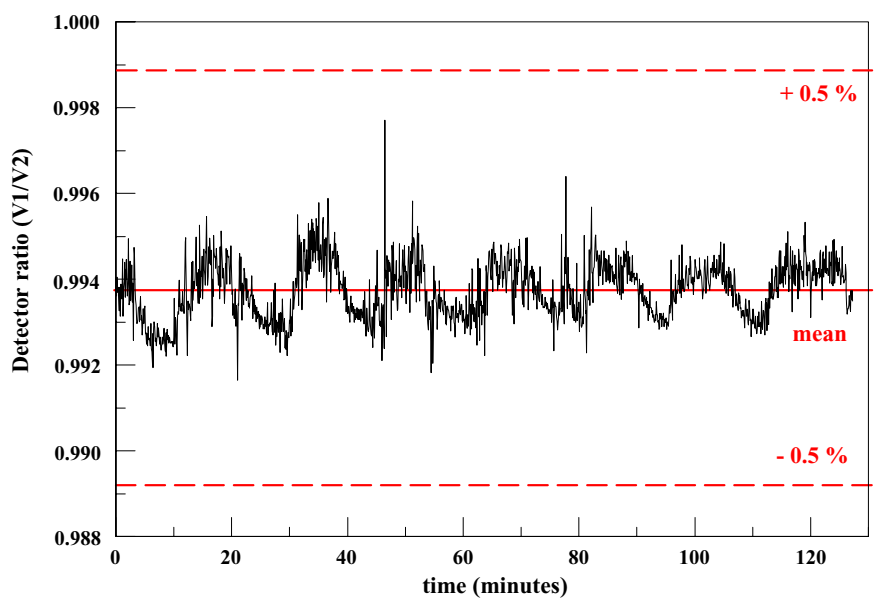

Figure 11. Short-Term Detector Stability

\subsection{Long-Term Detector Variability Tests}

These tests monitor the long-term variability of the optical detectors, including the effect of turning the system on and off. In these tests, PNNL records the data from each of the detectors for about 2 hours. After the first 3 weeks, we began taking data only twice a week. Figure 12 shows the ratio between the two detectors from August 6, 2003, until October 21, 2003. All of the data is well within the 2.5\% range, and the mean values are within the $1 \%$ range although some of the error bars fall outside of the $1 \%$ range. These results suggest the optical detectors should make a viable back-up for ensuring the QC Laser Alignment System is within the System Specifications. Because Maxion is planning to use a highly reflective coating on the rear facet of the QC laser to increase output power, PNNL estimates the power on the detector will only be in the microwatts range. These low signal levels will not only be hard to

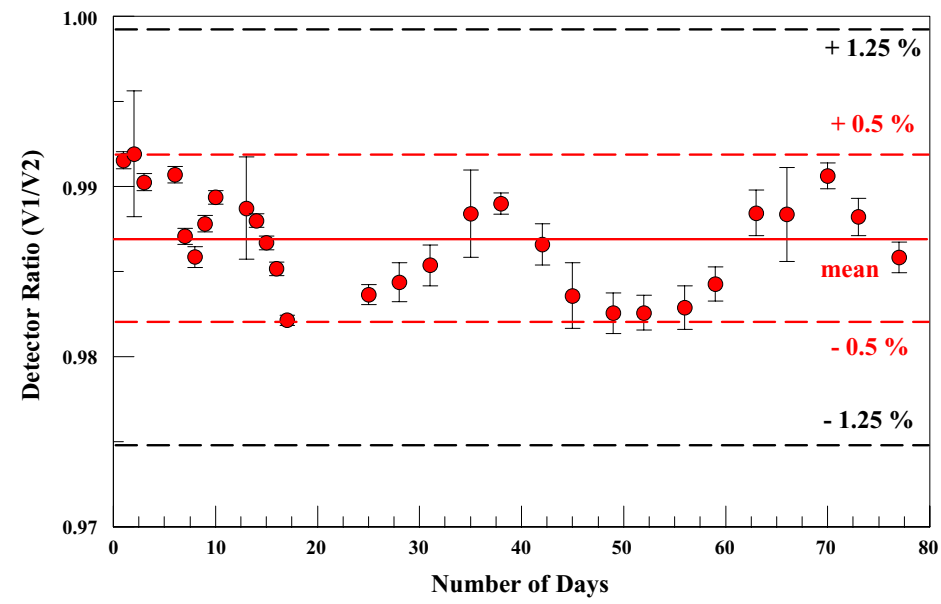

Figure 12. Detector Stability Measurements Over 80 Days 
detect but it will be nearly impossible to detect fluctuations at the $1 \%$ level. Thus, PNNL is planning to incorporate an electrical amplifier on the ASA to boost signal levels. The power requirements for the amplifier are minimal so we are just planning to use the current leads to the QC laser.

\subsection{Concluding Remarks}

These tests, particularly the power stability tests, show that too many different variables exist to really determine the outcome in the QC Laser Alignment System. Problems with the mounting scheme in the power stability tests caused power fluctuations with thermal cycling. In fact, these results are probably worsened by instabilities in the mount. PNNL is incorporating several improvements in the QC Laser Alignment System that is being developed. The QC lasers are being directly soldered to the ASA mount for the most stability, and the temperature sensor is located on the ASA mount for better temperature control. With these improvements, we expect higher performance with just temperature and current control. We will also use the remote sensing configuration with separate current and voltage sense leads for a more accurate measurement of the voltage for better monitoring. Improved monitoring of the voltage along with the on-board optical sensors will provide additional feedback. Although the 1\% stability is still near the limits of the performance expectations for the optical detectors, this requirement is only for the QC lasers on the same ASA mount so that it should be more easily achieved with just temperature and current control. 